University of Nebraska - Lincoln DigitalCommons@University of Nebraska - Lincoln

2016

Monoclonal antibodies to human butyrylcholinesterase reactive with butyrylcholinesterase in animal plasma

Hong Peng

Follow this and additional works at: http://digitalcommons.unl.edu/publichealthresources

Peng, Hong, "Monoclonal antibodies to human butyrylcholinesterase reactive with butyrylcholinesterase in animal plasma" (2016). Public Health Resources. 519.

http://digitalcommons.unl.edu/publichealthresources/519

This Article is brought to you for free and open access by the Public Health Resources at DigitalCommons@University of Nebraska - Lincoln. It has been accepted for inclusion in Public Health Resources by an authorized administrator of DigitalCommons@University of Nebraska - Lincoln. 


\title{
Monoclonal antibodies to human butyrylcholinesterase reactive with butyrylcholinesterase in animal plasma
}

\author{
Hong Peng a, Stephen Brimijoin ${ }^{\text {b }}$, Anna Hrabovska ${ }^{c}$, Eric Krejci ${ }^{d}$, Thomas A. Blake ${ }^{e}$, \\ Rudolph C. Johnson ${ }^{\mathrm{e}}$, Patrick Masson a , Oksana Lockridge ${ }^{\mathrm{a}, *}$ \\ ${ }^{a}$ Eppley Institute, University of Nebraska Medical Center, Omaha, NE, USA \\ b Department of Molecular Pharmacology and Experimental Therapeutics, Mayo Clinic, Rochester, MN, 55905, USA \\ ${ }^{\mathrm{c}}$ Department of Pharmacology and Toxicology, Faculty of Pharmacy, Comenius University in Bratislava, Bratislava, Slovakia \\ d Université Paris Descartes CNRS SSA COGNAC G UMR 825745 rue des Saints Pères, 75006, Paris, France \\ e Division of Laboratory Sciences, National Center for Environmental Health, Centers for Disease Control and Prevention, Atlanta, GA, 30341, USA
}

\section{A R T I C L E I N F O}

\section{Article history:}

Received 14 September 2015

Received in revised form

1 November 2015

Accepted 9 November 2015

Available online 14 November 2015

\section{Keywords}

Butyrylcholinesterase

Monoclonal antibody

Magnetic beads

Pansorbin

Nondenaturing gel

\begin{abstract}
A B S T R A C T
Five mouse anti-human butyrylcholinesterase (BChE) monoclonal antibodies bind tightly to native human BChE with nanomolar dissociation constants. Pairing analysis in the Octet system identified the monoclonal antibodies that bind to overlapping and independent epitopes on human BChE. The nucleotide and amino acid sequences of 4 monoclonal antibodies are deposited in GenBank. Our goal was to determine which of the 5 monoclonal antibodies recognize $\mathrm{BChE}$ in the plasma of animals. Binding of monoclonal antibodies 11D8, B2 18-5, B2 12-1, mAb2 and 3E8 to BChE in animal plasma was measured using antibody immobilized on Pansorbin cells and on Dynabeads Protein G. A third method visualized binding by the shift of $\mathrm{BChE}$ activity bands on nondenaturing gels stained for $\mathrm{BChE}$ activity. Gels were counterstained for carboxylesterase activity. The three methods agreed that B2 $18-5$ and mAb2 have broad species specificity, but the other monoclonal antibodies interacted only with human $\mathrm{BChE}$, the exception being 3E8, which also bound chicken BChE. B2 $18-5$ and $\mathrm{mAb} 2$ recognized $\mathrm{BChE}$ in human, rhesus monkey, horse, cat, and tiger plasma. A weak response was found with rabbit BChE. Monoclonal $\mathrm{mAb2}$, but not B2 18-5, bound pig and bovine BChE. Gels stained for carboxylesterase activity confirmed that plasma from humans, monkey, pig, chicken, and cow does not contain carboxylesterase, but plasma from horse, cat, tiger, rabbit, guinea pig, mouse, and rat has carboxylesterase. Rabbit plasma carboxylesterase hydrolyzes butyrylthiocholine. In conclusion monoclonal antibodies B2 18-5 and mAb2 can be used to immuno extract $\mathrm{BChE}$ from the plasma of humans, monkey and other animals.
\end{abstract}

๑) 2015 Elsevier Ireland Ltd. All rights reserved.

\section{Introduction}

Butyrylcholinesterase (BChE; EC 3.1.1.8) is a serine esterase that catalyzes the hydrolysis of acetylcholine, butyrylcholine, benzoylcholine, indoxyl acetate, p-nitrophenyl acetate, phenyl acetate, alpha-naphthyl acetate, aspirin, procaine, succinyldicholine,

Abbreviations: HuBChE, human butyrylcholinesterase; BSA, bovine serum albumin; CES, carboxylesterase; U, units of activity.

* Corresponding author. 985950 Nebraska Medical Center, Omaha, NE, 681985950, USA.

E-mail addresses: hong.peng@unmc.edu (H. Peng), brimijoi@mayo.edu (S. Brimijoin), hrabovska@fpharm.uniba.sk (A. Hrabovska), eric.krejci@ parisdescartes.fr (E. Krejci), fsi3@cdc.gov (T.A. Blake), rmj6@cdc.gov (R.C. Johnson), pmasson@unmc.edu (P. Masson), olockrid@unmc.edu (O. Lockridge). mivacurium, cocaine, heroin, irinotecan, bambuterol and octanoyl ghrelin [1-4]. Some of these esters are used as drugs to treat various human conditions. BChE also serves as a stoichiometric bioscavenger for organophosphorus pesticides and nerve agents, thus protecting acetylcholinesterase from irreversible inhibition by these toxic compounds [5].

Many drugs are synthesized as esters to neutralize their charge, thus allowing the drug to be absorbed through the gut and through cell membranes including cells in the brain. The esterified drug may be a prodrug that requires hydrolysis of the ester bond to become the active drug. For example, the antiasthma prodrug bambuterol is hydrolyzed to the active drug terbutaline by BChE [6]. Other ester drugs are detoxified by BChE. For example, BChE hydrolyzes cocaine to the pharmacologically inactive metabolites, ecgonine methyl ester and benzoic acid [7-9]. New drugs are tested in 
animals before they are tested in humans. Standard laboratory animals including the mouse, rat, guinea pig, and monkey have levels of $\mathrm{BChE}$ in plasma that are not representative of the level of $\mathrm{BChE}$ in human plasma. The rat has 30 -fold less plasma BChE compared to humans. Rhesus monkey has $2-3$ fold higher levels of $\mathrm{BChE}$ in plasma than humans. Another difference between animals and humans is that mouse, rat, and guinea pig have carboxylesterase in plasma, whereas humans and monkeys have none [4]. The plasma carboxylesterase in animals degrades drug esters rapidly, giving an inaccurate pharmacokinetic profile for drug metabolism in humans. The plasma carboxylesterase knockout mouse, ES1 - / - (Jackson Laboratory stock number 014096), can be used as a model for how humans metabolize an ester drug [10,11].

Knowledge of the identity of the esterase involved in metabolism of a drug is important because it leads to an understanding of individual differences in response to drugs. The atypical and silent variants of human $\mathrm{BChE}$ do not hydrolyze succinylcholine and mivacurium; consequently people with these genetic variants are unable to breathe for up to $2 \mathrm{~h}$ from a dose intended to paralyze for 3 min [12]. More than 70 variants of human BChE have been recognized [13]. Animal studies that aim to identify the role of $\mathrm{BChE}$ in drug metabolism may benefit by using an immobilized antibody to capture BChE. The captured BChE has activity and can be used directly to measure the role of $\mathrm{BChE}$ in ester hydrolysis, as we have done for octanoyl ghrelin [14]. Mrvova et al. produced two monoclonal antibodies in BChE knockout mice that recognize BChE in mouse, rat and dog plasma [15].

In a previous report [16] we characterized 5 mouse anti-human BChE monoclonal antibodies. We reported similar nanomolar binding affinities for all 5 monoclonal antibodies, but variable performance in their ability to immunopurify BChE from human plasma. Octet pairing analysis was carried out by immobilizing pure human BChE on a chip followed by measurement of the change in the interference pattern when antibody flowed over the chip. Pairing analysis showed that two pairs of antibodies, mAb2 and B2 $12-1$, as well as $\mathrm{mAb} 2$ and $3 \mathrm{E} 8$, bound to independent epitopes on human BChE and were therefore useful in sandwich assays. We deposited the nucleotide and amino acid sequences of 4 monoclonal antibodies in GenBank. The goal of the present work was to identify the monoclonal antibodies that recognize BChE in the plasma of animals. We describe 5 monoclonal antibodies to human $\mathrm{BChE}$, two of which have broad specificity enabling them to recognize $\mathrm{BChE}$ in the blood of human, monkey, horse, cat, and tiger.

\section{Materials and methods}

\subsection{Reagents}

2.1.1. Pansorbin cells $1 \mathrm{~g}$ (Calbiochem \#507862) coated with $1 \mathrm{ml}$ of rabbit anti-mouse IgG H + L (Jackson ImmunoResearch \#315-001003)

Dynabeads Protein G (Life Technologies \#10004D). ImmunoPure immobilized Protein G (Pierce \#20398). Human plasma Na Citrate pooled from 10 donors (UNMC blood bank); rhesus monkey plasma Na Heparin and horse serum (Atlanta Biologicals); cat plasma Na Citrate (Pel-Freeze); Bengal Tiger plasma EDTA anticoagulant (Omaha Henry Doorly Zoo); New Zealand white rabbit plasma Na Heparin, porcine serum, and rat serum (RJO Biologicals); guinea pig plasma Na Heparin and mouse strain 129 serum (Taconic); chicken plasma Na Heparin (Innovative Research Inc.); bovine calf serum (General Scientific Lab). Acetylthiocholine iodide, butyrylthiocholine iodide and ethopropazine hydrochloride (Sigma-Aldrich).

\subsubsection{Monoclonal antibodies to $\mathrm{HuBChE}$}

Mouse anti-human BChE monoclonal antibodies were from the following sources. Monoclonal 3E8 was purchased from Thermo Scientific Pierce (HAH 002-01-02); the original 3E8 monoclonal was made in Denmark [17]. Hybridoma cell line 11D8 was a gift from Dr. Eric Krejci and Dr. Anna Hrabovska [18]. We purified the 11D8 monoclonal from culture medium on Protein G-Sepharose. Hybridoma cell lines B2 18-5 and B2 12-1 were a gift from Dr. Stephen Brimijoin [19]. The cells, having been stored at $-80^{\circ} \mathrm{C}$ for 30 years, failed to grow but their RNA was still intact. Syd Labs Inc (Natick, MA) made the B2 18-5 and B2 12-1 monoclonal antibodies by recombinant DNA methods using mRNA as a template to make cDNA, followed by ligation of the cDNA into vectors that contained the constant regions, coexpression of the light and heavy chains in Chinese Hamster Ovary cells, and purification on protein A-Sepharose. Ascites fluid from B2 18-5 and B2 12-1 was available for comparison to the recombinant antibodies. The mAb2 monoclonal was made in France [20]. We purified mAb2 from ascites fluid.

\subsection{Nucleotide and amino acid sequences of monoclonal antibodies}

The nucleotide and amino acid sequences of mouse anti human BChE monoclonal antibodies are deposited in the NCBI databank under accession numbers KJ141199 and KJ141200 for mAb2, KT189143 and KT189144 for B2 18-5, KT189145 and KT189146 for B2 12-1, and KT189147 and KT189148 for 11D8. Use of these monoclonal antibodies for immunoextraction of $\mathrm{BChE}$ from human plasma is described in Ref. [16].

\subsection{BChE activity}

BChE activity was measured in $0.1 \mathrm{M}$ potassium phosphate $\mathrm{pH}$ 7.0 at $25^{\circ} \mathrm{C}$ with $1 \mathrm{mM}$ butyrylthiocholine iodide in the presence of $0.5 \mathrm{mM} 5,5^{\prime}$-dithiobis(2-nitrobenzoic acid) on a Gilford spectrophotometer interfaced to a MacLab data recorder (ADinstruments, Inc.). For example, a $4 \mathrm{ml}$ cuvette received $1.91 \mathrm{ml}$ buffer, $0.05 \mathrm{ml}$ of $20 \mathrm{mM}$ DTNB in buffer, $0.02 \mathrm{ml}$ of $0.1 \mathrm{M}$ butyrylthiocholine dissolved in water, and $0.02 \mathrm{ml}$ plasma. The increase in absorbance at $412 \mathrm{~nm}$ was recorded for $1 \mathrm{~min}$ and converted to micromoles butyrylthiocholine hydrolyzed using the extinction coefficient $13,600 \mathrm{M}^{-1} \mathrm{~cm}^{-1}$ [21]. Units (U) of activity are expressed as micromoles per min.

\subsection{Immunoadsorbance of BChE to monoclonal antibodies immobilized on pansorbin}

Pansorbin $^{\circledR}$ cells are an inexpensive alternative to DynabeadsProtein G for assessing species selectivity of 5 monoclonal antibodies. Pansorbin ${ }^{\circledR}$ cells are heat-killed, formalin-fixed Staphylococcus aureus cells that bear a high cell-surface density of protein A.

The Pansorbin assay was performed as described by Brimijoin et al. [19]. The effectiveness of Pansorbin for binding mouse monoclonal antibodies is enhanced when Pansorbin cells are coated with rabbit anti-mouse IgG. Therefore, the first step in the protocol was to incubate $1 \mathrm{~g}$ of washed Pansorbin cells suspended in $9 \mathrm{ml}$ of $50 \mathrm{mM}$ TrisHCl pH 7.4 containing $0.1 \%$ BSA with $1 \mathrm{ml}$ of $1 \mathrm{mg} / \mathrm{ml}$ rabbit anti-mouse IgG at $37^{\circ} \mathrm{C}$ overnight. A $0.1 \mathrm{ml}$ aliquot of rabbit anti-mouse IgG Pansorbin cell suspension was washed and incubated with $1 \mu \mathrm{g}$ monoclonal in a total volume of $0.2 \mathrm{ml}$ overnight. The control incubation contained Pansorbin cells and buffer, but no monoclonal. Unbound monoclonal was washed off. The washed Pansorbin complex was incubated overnight at room temperature on a rotating mixer with plasma or serum containing 13.5 milliunits of $\mathrm{BChE}$ supplemented with $50 \mathrm{mM}$ TrisHCl pH 7.4/ 
$0.1 \%$ BSA to total $0.2 \mathrm{ml}$. Plasma or serum was from human, rhesus monkey, horse, domestic cat, Bengal tiger, New Zealand white rabbit, pig, guinea pig, mouse, chicken, or adult cow. Rat plasma and bovine serum were added to the cells without buffer.

The Pansorbin cells were pelleted by centrifugation at $5000 \mathrm{rpm}$ for $4 \mathrm{~min}$. The supernatant was assayed for unbound BChE activity. The pellets were washed twice with $1 \mathrm{ml}$ buffer and finally with $1 \mathrm{ml}$ of $0.1 \mathrm{M}$ potassium phosphate, $\mathrm{pH}$ 7.0. The activity of BChE bound to Pansorbin cells was determined by measuring the yellow color that developed after addition of $1 \mathrm{ml}$ Ellman reagent $(1 \mathrm{mM}$ butyrylthiocholine, $0.5 \mathrm{mM}$ 5,5'-dithiobis(2-nitrobenzoic acid) in $0.1 \mathrm{M}$ potassium phosphate $\mathrm{pH}$ 7.0) to the washed pellet. The reaction was stopped after 10 min by addition of $20 \mu \mathrm{l}$ of $2.0 \mathrm{mM}$ ethopropazine, a specific inhibitor of BChE activity. After centrifugation at $12,000 \mathrm{rpm}$ for 10 min to pellet the turbidity from Pansorbin cells, absorbance of the supernatant was read in the Gilford spectrophotometer at $412 \mathrm{~nm}$. Fig. 1A illustrates antibodies and $\mathrm{BChE}$ bound to Pansorbin and detection of bound BChE by measurement of bound BChE activity.

\subsection{Dynabeads-Protein $G$ for immunopurification of BChE from plasma or serum}

Immunopurification of HuBChE from human plasma in a single step was developed by Sporty et al. to enable mass spectrometry diagnosis of exposure to chemical nerve agents [22]. In the present work we used the Sporty protocol to compare 5 monoclonal antibodies for ability to extract BChE from the plasma or serum of animals. We evaluated the quantity of BChE bound by comparing BChE activity in the unbound fraction to BChE activity in plasma before treatment with Dynabeads.

In brief, $100 \mu$ l of Dynabeads-Protein G suspension was washed three times with $200 \mu$ of PBS, followed by incubation overnight with $20 \mu$ g of monoclonal antibody in $0.4 \mathrm{ml}$ PBS containing $0.05 \%$ Tween-20. The Dynabead complex was washed twice with $200 \mu \mathrm{l}$ of triethanolamine buffer $\left(0.2 \mathrm{M}\right.$ triethanolamine, $0.025 \% \mathrm{NaN}_{3}, \mathrm{pH}$ 7.8), before the complex was crosslinked with $200 \mu$ l of dimethyl pimelimidate $(5.4 \mathrm{mg} / \mathrm{ml})$ in triethanolamine buffer for $30 \mathrm{~min}$. The crosslinking solution was discarded and residual agent was inactivated by incubating the beads for $15 \mathrm{~min}$ in $20 \mathrm{mM}$ Tris $\mathrm{HCl} \mathrm{pH} 7.5$. Beads were washed 3 times with $200 \mu$ of PBS, $0.05 \%$ Tween-20 before they were incubated with $0.5 \mathrm{ml}$ human, monkey, horse, cat, guinea pig, mouse and chicken plasma or serum, and $5 \mathrm{ml}$ rabbit, pig, rat or bovine plasma or serum overnight at room temperature in a rotating mixer. We did not have enough tiger plasma to assay binding of tiger BChE to Dynabeads. BChE activity assays were used to evaluate the quantity of BChE bound. Fig. 1B shows BChE enzyme captured by anti-BChE antibody immobilized on Dynabeads Protein $G$ and detection of bound BChE by measurement of bound BChE activity.

\subsection{Nondenaturing polyacrylamide gel electrophoresis}

Animal plasma or serum samples $(5 \mu \mathrm{l})$ were incubated $3 \mathrm{~h}$ at $25{ }^{\circ} \mathrm{C}$ with or without $10 \mu \mathrm{l}$ of monoclonal B2 $18-5(0.9 \mathrm{mg} / \mathrm{ml})$ or $10 \mu \mathrm{l}$ of $\mathrm{mAb} 2(0.6 \mathrm{mg} / \mathrm{ml})$ for $3 \mathrm{~h}$ at $25^{\circ} \mathrm{C}$ before they were diluted with an equal volume of $50 \%$ glycerol, $0.1 \%$ bromphenol blue. Samples were loaded on nondenaturing 4-30\% gradient polyacrylamide gels and electrophoresed at $250 \mathrm{~V}$ constant voltage for $20 \mathrm{~h}$ at $4{ }^{\circ} \mathrm{C}$. The gels were stained for BChE activity by the method of Karnovsky and Roots [23]. The staining solution contained $180 \mathrm{ml}$ of $0.2 \mathrm{M}$ maleic acid adjusted to $\mathrm{pH} 6.0$ before use, $15 \mathrm{ml}$ of $0.1 \mathrm{M}$ sodium citrate, $30 \mathrm{ml}$ of $0.03 \mathrm{M} \mathrm{CuSO}_{4}, 30 \mathrm{ml}$ of water, $30 \mathrm{ml}$ of $5 \mathrm{mM}$ potassium ferricyanide, and $0.18 \mathrm{~g}$ butyrylthiocholine iodide to make $2 \mathrm{mM}$ butyrylthiocholine. Gels were incubated in the buffer for $2 \mathrm{~h}$ with gentle shaking until brown-red bands appeared. Gels were counterstained for carboxylesterase (CES) activity by incubating them in $100 \mathrm{ml}$ of $50 \mathrm{mM}$ Tris $\mathrm{HCl} \mathrm{pH} 8.0$ to which was added $50 \mathrm{mg}$ of alpha-naphthylacetate in $1 \mathrm{ml}$ ethanol to make $2.7 \mathrm{mM}$, and $50 \mathrm{mg}$ of solid Fast Blue RR [4]. Green bands developed within a few minutes.

\subsection{Comparison of BChE amino acid sequences}

The protein sequence of HuBChE was compared with the BChE sequences of rhesus monkey, horse, cat, Bengal tiger, pig, guinea pig, mouse, rat, chicken, and cow using BLASTP 2.2.30+ [24]. The sequence comparison results are presented as percent identity.

\section{Results}

\subsection{Butyrylcholinesterase activity in animal plasma or sera}

$\mathrm{BChE}$ activity varied widely between species. Table 1 shows the highest BChE activity in Rhesus monkey plasma, similar BChE activities in human, horse, and mouse, low activity in the cat, tiger, rabbit, pig, and chicken, and barely detectable BChE activity in rat plasma and adult bovine serum.

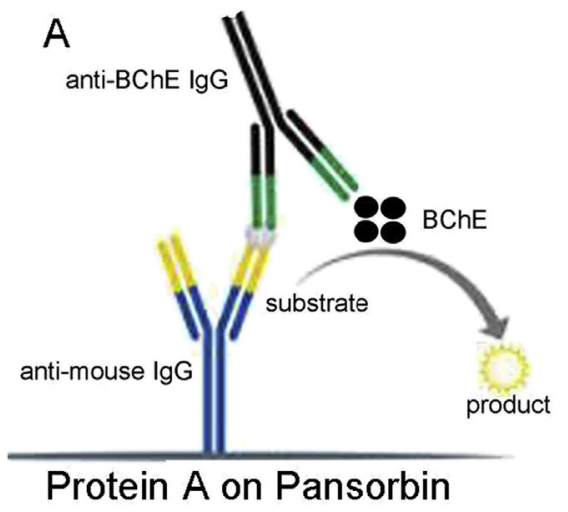

B

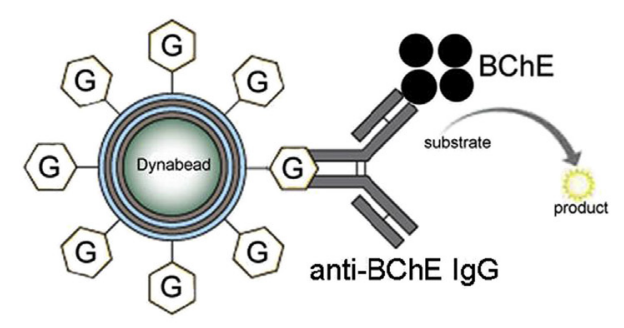

Dynabeads Protein $G$

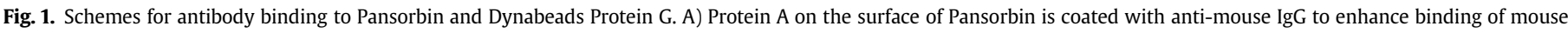

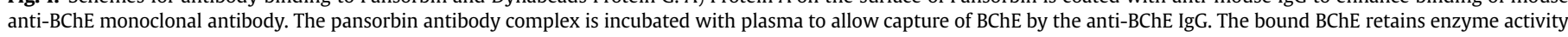

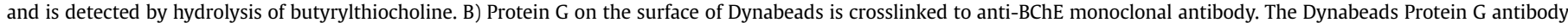

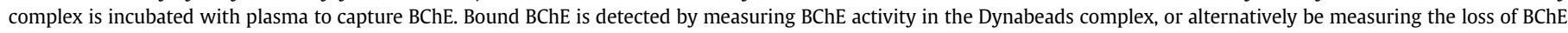
activity from plasma. 
Table 1

$\mathrm{BChE}$ activity in plasma or serum.

\begin{tabular}{lc}
\hline Species & BChE activity, U/ml a \\
\hline Human (Homo sapiens) plasma & $2.50 \pm 0.02$ \\
Rhesus monkey (Macaca mulatta) plasma & $5.00 \pm 0.18$ \\
Horse (Equus caballus) serum & $2.26 \pm 0.10$ \\
Cat (Felis catus) plasma & $0.40 \pm 0.01$ \\
Bengal Tiger (Panthera tigris tigris) serum & $0.60 \pm 0.01$ \\
Rabbit (Oryctolagus cuniculus) plasma & $0.13 \pm 0.03$ \\
Pig (Sus scrofa domesticus) serum & $0.19 \pm 0.01$ \\
Guinea pig (Cavia porcellus) plasma & $1.26 \pm 0.06$ \\
Mouse (Mus musculus) serum & $2.51 \pm 0.11$ \\
Rat (Rattus norvegicus) plasma & $0.058 \pm 0.012$ \\
Chicken (Gallus gallus) plasma & $0.30 \pm 0.02$ \\
Cow (Bos taurus) serum & $0.05 \pm 0.02$ \\
\hline
\end{tabular}

${ }^{\mathrm{a}}$ BChE activity was assayed in quadruplicate.

\subsection{B2 $18-5$ and $m A b 2$ recognize butyrylcholinesterase from different species}

The reactivity of five anti-human $\mathrm{BChE}$ monoclonal antibodies with $\mathrm{BChE}$ in the blood of animals was compared by measuring immunoabsorbance to monoclonal antibodies immobilized on Pansorbin cells or Dynabeads Protein G. The percent BChE bound to Pansorbin cells was calculated by measuring the BChE activity bound to Pansorbin cells. The percent BChE bound to Dynabeads was calculated by comparing BChE activity in the unbound supernatant to activity in plasma/serum. The results in Fig. 2A for assays performed with Pansorbin are similar to the results in Fig. 2B for assays with Dynabeads Protein G, with some exceptions. The Pansorbin assay used a constant quantity of BChE activity (13.5 milliunits) whereas the Dynabeads Protein $G$ assay used a constant volume of plasma $(0.5 \mathrm{ml})$ per incubation reaction, except for rabbit, pig, rat, and cow where the volume of plasma was $5 \mathrm{ml}$. Fig. 2A shows that in the Pansorbin assay all 5 monoclonal antibodies bound $45-60 \%$ of the 13.5 milliunits of BChE activity in human plasma. Fig. 2B shows that in the Dynabeads assay B2 18-5 and B2 12-1 captured nearly 100\% of the BChE activity in $0.5 \mathrm{ml}$ human plasma, while $\mathrm{mAb} 2$ and 3E8 captured $60-70 \%$, and 11D8 captured $10 \%$ of the BChE in human plasma. Monoclonal antibodies 11D8 and B2 12-1 bound human BChE exclusively, whereas 3E8 bound human and chicken BChE. Chicken BChE was captured by $20 \mu \mathrm{g}$ 3E8 in the Dynabeads assay, but not by $1 \mu \mathrm{g}$ 3E8 in the Pansorbin assay.

Monoclonal antibodies B2 $18-5$ and $\mathrm{mAb} 2$ had the broadest species specificity, capturing $\mathrm{BChE}$ in human, rhesus monkey, horse, cat, and rabbit plasma/serum. B2 18-5 and mAb2 also captured $\mathrm{BChE}$ in the plasma of Bengal tiger in the Pansorbin assay. We have no data for tiger $\mathrm{BChE}$ in the Dynabeads assay because the quantity of tiger plasma available to us was limited. The BChE in pig, guinea pig, mouse, rat, chicken, and cow plasma/serum was not recognized by B2 $18-5$. However, pig and cow BChE were captured by $\mathrm{mAb} 2$, though the quantity captured was low because these animals have low $\mathrm{BChE}$ activity in plasma. The low $\mathrm{BChE}$ activity in pig and cow plasma resulted in large values for the standard deviation.

BChE activity without and with monoclonal antibody was visualized on nondenaturing gels stained for BChE activity. In Fig. 3, $5 \mu \mathrm{l}$ of plasma or serum samples were loaded per lane. Band intensities correlate with $\mathrm{BChE}$ activities reported in Table 1. Animal plasma or sera that have BChE activity of $0.4-5 \mathrm{U} / \mathrm{ml}$ (human, monkey, horse, cat, tiger, guinea pig and mouse) have strong bands of BChE activity in Fig. 3A lanes 1, 3, 5, 7, 9, 15 and 17. However, animal plasma or sera that have BChE activity of $0.04-0.3 \mathrm{U} / \mathrm{ml}$ (rabbit, pig, rat, chicken, and cow) have weak bands of BChE activity in Fig. 3A lanes 11, 13, 19, 21, and 23.

The tetramer band of human $\mathrm{BChE}, \mathrm{C} 4$, has a molecular weight of 340,000 Da. The dimer band, C3, is composed of two identical $\mathrm{BChE}$ subunits. However the dimer band, $\mathrm{C} 2$, consists of one $\mathrm{BChE}$ subunit and one albumin molecule linked via a disulfide bond [25]. Fig. $3 \mathrm{~A}$ shows that human, horse, cat, tiger, and mouse have a $\mathrm{C} 2$ band, but monkey and guinea pig do not. The monomer band, C1, is thought to be a partially proteolysed $\mathrm{BChE}$ that is missing the 40 residue-tetramerization domain at the $\mathrm{BChE} \mathrm{C-terminal.}$

$\mathrm{BChE}$ from human, rhesus monkey, horse, cat, tiger, guinea pig, and mouse resolved into monomer, dimer and tetramer bands on the nondenaturing gels in Fig. 3A, whereas BChE from rabbit, rat, and chicken merely showed tetramer bands. Minor BChE bands are probably present in the plasma of rabbit, rat, and chicken, but their concentration is below the limit of detection. The dominant form of $\mathrm{BChE}$ in human, monkey, horse, cat, tiger, rabbit, mouse, rat, and chicken plasma is a tetramer. However, the dominant form of $\mathrm{BChE}$ in guinea pig plasma is a dimer. Bands of BChE activity in human, monkey, horse, and mouse plasma that migrate more slowly than the BChE tetramer C4 are called storage bands because they are not present in freshly drawn plasma, but appear in plasma that has been stored.

Incubation of plasma with monoclonal B2 $18-5$ in Fig. 3A shifted the bands of $\mathrm{BChE}$ activity to slower migrating forms that represent a complex of $\mathrm{BChE}$ with antibody. Band shifts are clearly visible for human, monkey, horse, and cat plasma incubated with B2 18-5 (Fig. 3A lanes 2, 4, 6, 8), but are less evident for tiger plasma (Fig. 3A lane 10). The BChE band for rabbit plasma disappeared in the sample incubated with B2 18-5 (Fig. 3A lane 12). In contrast, band shifts are not seen for B2 $18-5$ incubated with plasma from pig, guinea pig, mouse, rat, chicken and cow, supporting the conclusion that B2 18-5 does not bind to BChE from these species. The nondenaturing gel in Fig. 3A supports the Pansorbin and Dynabeads results for monoclonal $\mathrm{B} 2 \mathrm{18}-5$ by visually demonstrating the interaction of antibody with $\mathrm{BChE}$ from selected species.

The gel in Fig. $3 \mathrm{~A}$ was counterstained with alphanaphthylacetate and Fast Blue RR to reveal carboxylesterase activity in Fig. 3B. Carboxylesterase activity (CES) is seen as a dark green band above albumin. Horse, cat, tiger, rabbit, guinea pig, mouse, and rat have carboxylesterase in plasma, but human, monkey, pig, chicken, and cow have no carboxylesterase in plasma.

Binding of 3E8 to chicken BChE is visualized in Fig. 4 where the band for chicken $\mathrm{BChE}$ in lane 3 disappears following incubation with 3E8 (lane 4). The chicken BChE complex with 3E8 is assumed to have become too large to enter the gel. In contrast, incubation of chicken plasma with monoclonal B2 18-5 (Fig. 3A lane 22) had no effect on the mobility of chicken BChE, supporting the conclusion that chicken BChE does not bind to B2 18-5. BChE activity bands in human plasma shift to slower migrating forms following incubation with 3E8 (Fig. 4 lane 2); the broad smear of BChE activity in the stacking gel (Fig. 4 lane 2) indicates that the human BChE complex with 3E8 is heterogeneous and very large.

Table 2 compares the reactivity of monoclonals B2 18-5 and mAb2 with BChE in the plasma of 12 species as measured in 3 different assays.

\subsection{BChE amino acid sequence comparisons}

We used BLASTP 2.2.30 + to compare the protein sequence of human BChE with BChE from rhesus monkey, horse, cat, Bengal tiger, rabbit, pig, guinea pig, mouse, rat, chicken, and cow. The BLAST analysis revealed sequence identities of $72-96 \%$ (Table 3).

The BChE sequences of twelve species were aligned in Supplementary Fig. S5. Residues important for enzyme hydrolysis are present in all species. The low plasma BChE activity in some 

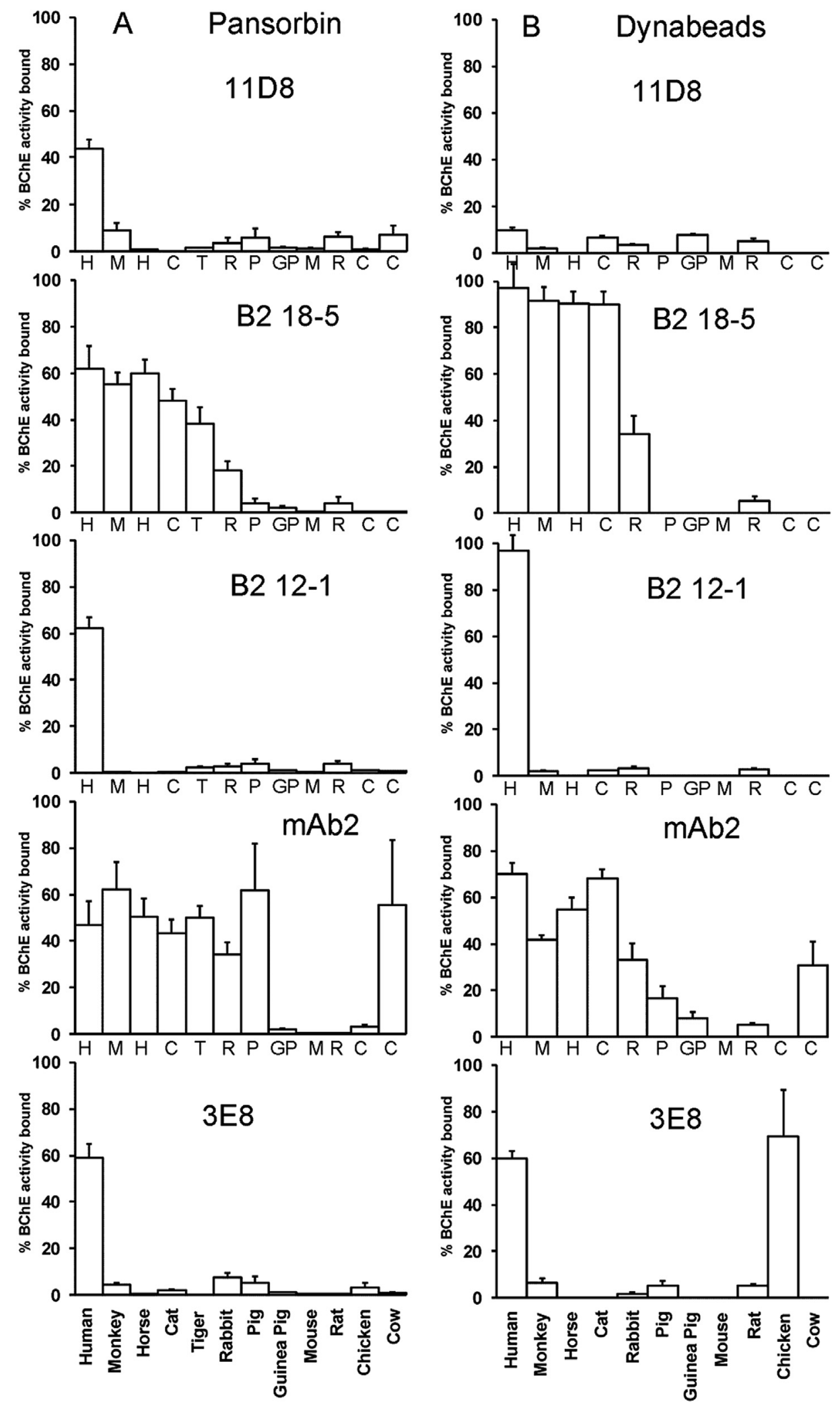

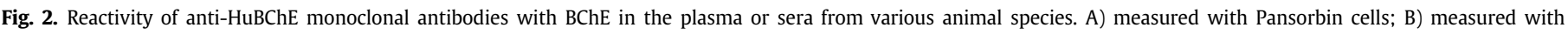
Dynabeads protein $\mathrm{G}$.

species could be the consequence of amino acid sequence differences in regions not recognized as being important for catalysis or stability. Differences in the promoter and in the sequence around the translation start site could also explain low plasma $\mathrm{BChE}$ activity.

Amino acid sequence identity does not predict which animal $\mathrm{BChE}$ will be recognized by monoclonal antibodies to human $\mathrm{BChE}$. For example, though horse $\mathrm{BChE}$ and bovine $\mathrm{BChE}$ protein 


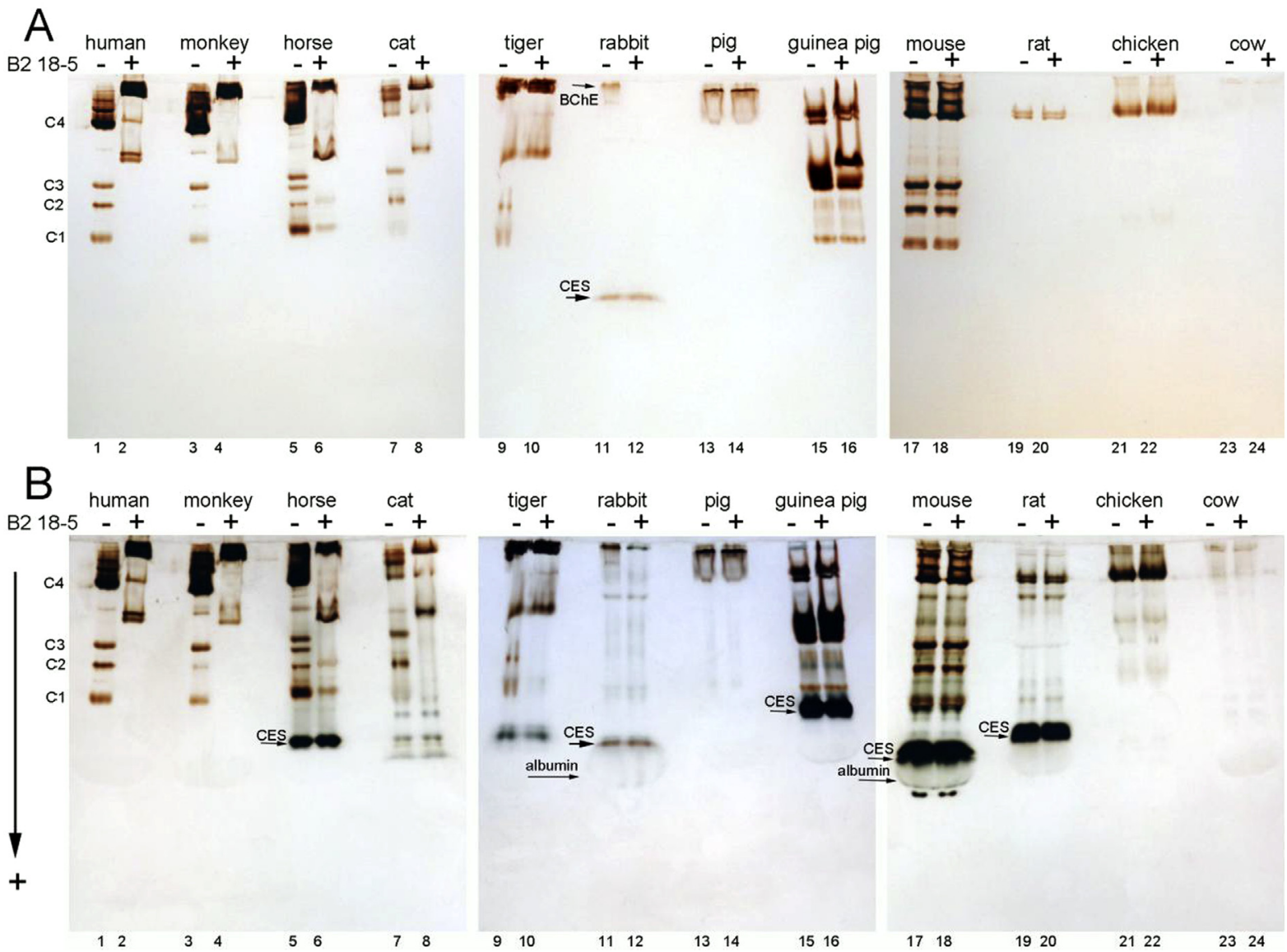

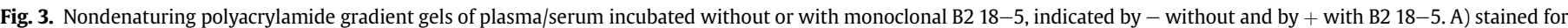

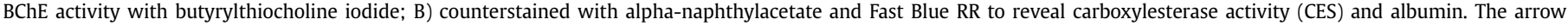

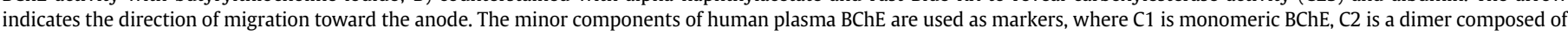
one BChE subunit covalently bound to one albumin molecule, $\mathrm{C} 3$ is a $\mathrm{BChE}$ dimer, and $\mathrm{C} 4$ is the $\mathrm{BChE}$ tetramer.

sequences are $90 \%$ identical to human BChE, monoclonal B2 18-5 binds horse BChE but not bovine BChE.

\section{Discussion}

\subsection{Mammals with very low BChE activity in plasma}

All the animals in the present study have one BCHE gene and mRNA encoding the BChE protein. BChE activity varies 100-fold from a low of $0.05 \mathrm{U} / \mathrm{ml}$ in rat to $5.0 \mathrm{U} / \mathrm{ml}$ in rhesus monkey plasma. A similar species difference in plasma BChE activity was reported by Augustinsson, who assayed activity with butyrylcholine by the Warburg method [26]. Plasma of cow, goat and sheep had barely detectable levels of BChE activity, while plasma of rabbit, rat and swine had slightly higher but still 20-fold lower BChE activity compared to human plasma.

A generally accepted function of $\mathrm{BChE}$ is to detoxify poisons that are eaten or inhaled. Animals with the lowest plasma BChE levels might be expected to have compensating plasma carboxylesterase activity. Rabbit and rat have carboxylesterase in plasma, but pig, chicken, and cow have no carboxylesterase in plasma. Another function of BChE is hydrolysis of the neurotransmitter acetylcholine. BChE acts as an independent and complementary modulator of acetylcholine levels at the mouse neuromuscular junction [27].

\subsection{Monoclonal antibodies that recognize BChE in animal plasma}

Monoclonal antibodies B2 $18-5$ and B2 $12-1$ were created by
Brimijoin et al. in mouse against human BChE [19]. They tested their monoclonal antibodies in the Pansorbin assay for ability to bind $\mathrm{BChE}$ in the plasma of various species and found that B2 $18-5$ binds $\mathrm{BChE}$ in human, squirrel monkey, dog, cat, and horse plasma, but does not bind $\mathrm{BChE}$ in guinea pig, chicken and rat plasma. B2 18-5 was weak in binding BChE in rabbit plasma. B2 12-1 bound only human BChE. In a second study, B2 12-1 bound serum BChE in higher primates in the order of affinity by species: man $>$ chimpanzee $=$ pygmy chimpanzee $>$ gorilla $>>$ orangutan $>$ gibbon [28] with $\mathrm{Kd}$ values ranging from $2.8 \mathrm{nM}$ to $74 \mathrm{nM}$. In contrast, B2 18-5 discriminated only marginally between the BChE of apes and man [28].

The B2 18-5 monoclonal we tested was expressed in Chinese Hamster Ovary cells. The B2 12-1 monoclonal was expressed in human HEK 293 cells. Our results agree with those of Brimijoin et al. [19]. In conclusion the B2 18-5 and B2 12-1 monoclonal antibodies produced by recombinant DNA methods have the same species specificity as the monoclonal antibodies secreted by mouse hybridoma cells.

Monoclonal mAb2 was created in mouse against human $\mathrm{BChE}$ [20]. Similar to B2 $18-5$, monoclonal $\mathrm{mAb} 2$ has broad species specificity. Pairing analysis on the Octet Red96 system showed that $\mathrm{mAb} 2$ and B2 18-5 bind to overlapping but not identical epitopes on HuBChE [16]. B2 18-5 paired with MAb2 when B2 18-5 was the capture antibody, but not in the reverse format when mAb2 was the capture antibody. The observation that $\mathrm{mAb} 2$ binds to an epitope that is not completely identical to the epitope recognized by B2 $18-5$ justifies our finding that their species specificities have some 


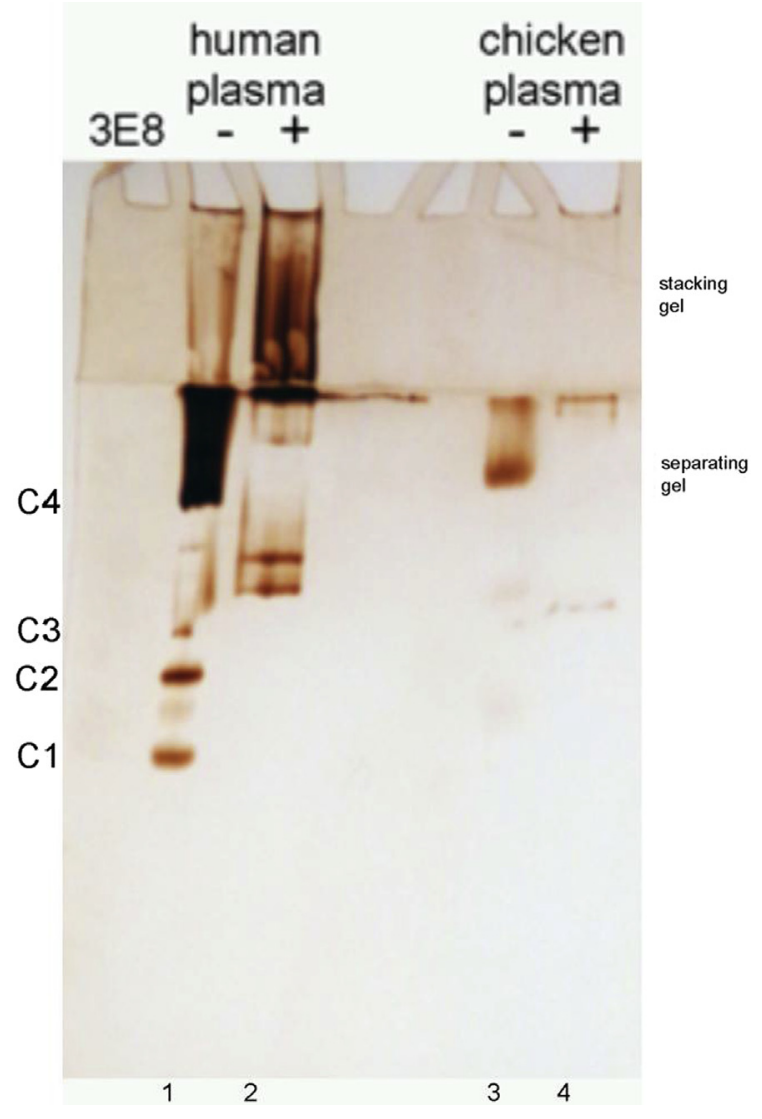

Fig. 4. Chicken $\mathrm{BChE}$ binds monoclonal antibody 3E8. Plasma $(5 \mu \mathrm{L})$ was incubated without or with monoclonal $3 \mathrm{E} 8(10 \mu \mathrm{L})$, indicated by - without and by + with $3 \mathrm{E} 8$. Following incubation, the samples were subjected to nondenaturing gradient gel electrophoresis. The gel was stained for BChE activity. Lane 1, human plasma. Lane 2, human plasma $+3 \mathrm{E} 8$. Lane 3, chicken plasma. Lane 4 , chicken plasma $+3 \mathrm{E} 8$. The $4 \%$ stacking gel contains a large-sized complex of human BChE and 3E8 (lane 2).

differences. Monoclonal mAb2, but not B2 $18-5$, binds BChE in the plasma of cow and pig.

None of the monoclonal antibodies in the present report recognized mouse BChE. A unique strategy for producing antimouse $\mathrm{BChE}$ antibodies in mice was introduced by Hrabovska et al. [18]. They immunized BChE knockout mice with recombinant mouse BChE and obtained highly efficient monoclonal antibodies that bind mouse BChE with Kd values in the nanomolar range [15]. No other laboratory has generated a monoclonal to mouse BChE.

\subsection{Carboxylesterase in rabbit plasma hydrolyzes butyrylthiocholine}

Rabbit plasma has two prominent bands of butyrylthiocholine hydrolase activity on a nondenaturing gel. The band near the top of the separating gel is BChE (P21927 UniProtKB). The band that migrates far into the gel is rabbit plasma carboxylesterase (CES). As a general rule carboxylesterases hydrolyze neutral esters but not positively charged esters. The carboxylesterase in rabbit plasma is an exception because it hydrolyzes the positively charged butyrylthiocholine. A previous report named the rabbit plasma carboxylesterase "monomeric BChE" [29]. However, Jbilo et al. concluded that "monomeric BChE" in rabbit plasma is carboxylesterase [30]. The rabbit plasma carboxylesterase did not bind to procainamide-affinity gel, it was not inhibited significantly by the specific BChE inhibitors eserine and iso-OMPA, and it preferred indoxyl acetate as a substrate. The existence of only one BCHE gene in the rabbit genome means there is no support for two pharmacologically distinct BChE proteins.

Our results support the conclusion of Jbilo et al. [30] that the butyrylthiocholine hydrolase that migrates adjacent to albumin in Fig. 3 (lanes 11 and 12) is rabbit carboxylesterase. The carboxylesterases in horse, cat, tiger, rabbit, guinea pig, mouse, and rat plasma consistently migrate adjacent to albumin and stain with alpha-naphthylacetate. Bahar et al. also agreed that this second band of butyrylthiocholine hydrolase activity is the activity of rabbit carboxylesterase [31]. We found that monoclonal antibodies B2 $18-5$ and $\mathrm{mAb} 2$ shifted the position of rabbit BChE, but not rabbit CES, supporting the conclusion that the butyrylthiocholine hydrolase labeled BChE in Fig. 3 lanes 11 and 12 is BChE, while the band labeled CES is carboxylesterase.

Additional support for our conclusion that CES in Fig. 3 lanes 11 and 12 is carboxylesterase comes from studies of the hereditary deficiency of atropine esterase in rabbits. Rabbits deficient in atropine esterase do not have a band of butyrylthiocholine hydrolase activity adjacent to albumin on a nondenaturing gel [30]. The atropine esterase in rabbit serum is a carboxylesterase with a molecular weight of 65,000 , similar to the molecular weight of albumin. The purified atropine esterase (carboxylesterase) has low but detectable activity with the positively charged esters acetylcholine, butyrylcholine, and benzoylcholine [32]. Carboxylesterases from rabbit liver also hydrolyze butyrylthiocholine though activity is detected only with $10-100 \mathrm{mM}$ butyrylthiocholine concentrations and not with the $1 \mathrm{mM}$ concentration that is standard for BChE activity assays [33]. Carboxylesterases are encoded by multiple genes. The NCBI database lists 25 genes for rabbit carboxylesterases all located on adjacent sites within chromosome 5NC_013673.1. The carboxylesterase in rabbit plasma is encoded by a different gene than the carboxylesterases in rabbit liver.

Table 2

Species specificity of monoclonal antibodies B2 $18-5$ and mAb2 for BChE assayed on Pansorbin, Dynabeads, and nondenaturing PAGE.

\begin{tabular}{|c|c|c|c|c|c|c|}
\hline & Pansorbin B2 18-5 & Dynabeads B2 18-5 & PAGE B2 18-5 & Pansorbin mAb2 & Dynabeads mAb2 & PAGE mAb2 \\
\hline Human & ++ & ++ & ++ & ++ & ++ & ++ \\
\hline Monkey & ++ & ++ & ++ & ++ & ++ & ++ \\
\hline Horse & ++ & ++ & ++ & ++ & ++ & ++ \\
\hline Cat & ++ & ++ & ++ & ++ & ++ & ++ \\
\hline Tiger & ++ & & + & ++ & & + \\
\hline Rabbit & + & + & + & + & + & - \\
\hline Pig & - & - & - & ++ & + & - \\
\hline Guinea pig & - & - & - & - & - & - \\
\hline Mouse & - & - & - & - & - & - \\
\hline Rat & - & - & - & - & - & - \\
\hline Chicken & - & - & - & - & - & - \\
\hline Cow & - & - & - & ++ & + & - \\
\hline
\end{tabular}

++indicates strong binding; + weak binding; - no binding to monoclonal. 
Table 3

$\mathrm{BChE}$ protein sequence identities of various species.

\begin{tabular}{|c|c|c|c|c|}
\hline Species & $\mathrm{NCBI}^{\mathrm{a}}$ & Swiss Prot $^{\mathrm{a}}$ & Amino acids & Identity \% \\
\hline Human (Homo sapiens) & AAA98113 & P06276 & 602 & $100 \%$ \\
\hline Rhesus Monkey (Macaca mulatta) & AFE79500.1 & - & 602 & $96 \%$ \\
\hline Horse (Equus caballus) & AAF61480.1 & Q9N1N9 & 602 & $90 \%$ \\
\hline Cat (Felis catus) & AAC06261.1 & 062760 & 602 & $87 \%$ \\
\hline Bengal Tiger (Panthera tigris tigris) & AAC06262.1 & 062761 & 602 & $87 \%$ \\
\hline Rabbit (Oryctolagus cuniculus) & XP_002716414.1 & P21927 & 601 & $91 \%$ \\
\hline Pig (Sus scrofa domesticus) & XP_003358712.1 & - & 602 & $89 \%$ \\
\hline Guinea Pig (Cavia porcellus) & XP_003469406.1 & H0V4F8 & 602 & $83 \%$ \\
\hline Mouse (Mus musculus) & AAA37328.1 & Q499C7 & 603 & $80 \%$ \\
\hline Rat (Rattus norvegicus) & NP_075231 & Q9JKC1 & 597 & $80 \%$ \\
\hline Chicken (Gallus gallus) & САС 37792.1 & Q90ZK8 & 603 & $72 \%$ \\
\hline Cow (Bos taurus) & AAI23601 & P32749 & 602 & $90 \%$ \\
\hline
\end{tabular}

${ }^{a}$ Accession numbers for BChE proteins in the NCBI and Swiss Protein databases are listed. Dash (-) indicates partial or absent sequence in the Swiss Protein database as of October 2015.

\section{Funding}

Supported by DLS/NCEH/CDC contracts 200-2012-M-53381 and 200-2013-57169 (to OL), a grant from the Minnesota Partnership for Biotechnology and Medical Genomics (to SB), grant VEGA 1/ 0855/15 (to AH), Association Française contre les Myopathies (to EK and $\mathrm{AH}$ ), and a Université Paris Descartes collaborative grant (to EK), the Centers for Disease Control and Prevention (to TAB and RCJ), Office of Public Health Preparedness and Response (to TAB and RCJ), and the Defense Threat Reduction Agency (11-005-12430) (to $\mathrm{TAB}$ and $\mathrm{RCJ}$ ).

\section{Disclaimer}

The findings and conclusions in this article are those of the authors and do not necessarily represent the views of the Centers for Disease Control and Prevention. Use of trade names is for identification only and does not imply endorsement by the Centers for Disease Control and Prevention, the Public Health Service, or the U.S. Department of Health and Human Services.

\section{Conflict of interest statement}

The authors have no competing interests.

\section{Appendix A. Supplementary data}

Supplementary data related to this article can be found at http:// dx.doi.org/10.1016/j.cbi.2015.11.011.

\section{Transparency document}

Transparency document related to this article can be found online at http://dx.doi.org/10.1016/j.cbi.2015.11.011.

\section{References}

[1] V.P. Chen, Y. Gao, L. Geng, R.J. Parks, Y.P. Pang, S. Brimijoin, Plasma butyrylcholinesterase regulates ghrelin to control aggression, Proc. Natl. Acad. Sci. U. S. A. 112 (2015) 2251-2256.

[2] T. Fukami, T. Yokoi, The emerging role of human esterases, Drug Metab. Pharmacokinet. 27 (2012) 466-477.

[3] B.M. Liederer, R.T. Borchardt, Enzymes involved in the bioconversion of esterbased prodrugs, J. Pharm. Sci. 95 (2006) 1177-1195.

[4] B. Li, M. Sedlacek, I. Manoharan, R. Boopathy, E.G. Duysen, P. Masson, O. Lockridge, Butyrylcholinesterase, paraoxonase, and albumin esterase, but not carboxylesterase, are present in human plasma, Biochem. Pharmacol. 70 (2005) 1673-1684.

[5] A. Saxena, W. Sun, P.A. Dabisch, S.W. Hulet, N.B. Hastings, E.M. Jakubowski, R.J. Mioduszewski, B.P. Doctor, Pretreatment with human serum butyrylcholinesterase alone prevents cardiac abnormalities, seizures, and death in
Gottingen minipigs exposed to sarin vapor, Biochem. Pharmacol. 82 (2011) 1984-1993.

[6] A. Tunek, L.A. Svensson, Bambuterol, a carbamate ester prodrug of terbutaline, as inhibitor of cholinesterases in human blood, Drug Metab. Dispos. 16 (1988) $759-764$.

[7] F. Zheng, W. Yang, M.C. Ko, J. Liu, H. Cho, D. Gao, M. Tong, H.H. Tai, J.H. Woods, C.G. Zhan, Most efficient cocaine hydrolase designed by virtual screening of transition states, J. Am. Chem. Soc. 130 (2008) 12148-12155.

[8] V. Murthy, Y. Gao, L. Geng, N.K. LeBrasseur, T.A. White, R.J. Parks, S. Brimijoin, Physiologic and metabolic safety of butyrylcholinesterase gene therapy in mice, Vaccine 32 (2014) 4155-4162.

[9] D.J. Stewart, T. Inaba, B.K. Tang, W. Kalow, Hydrolysis of cocaine in human plasma by cholinesterase, Life Sci. 20 (1977) 1557-1563.

[10] E.G. Duysen, F. Koentgen, G.R. Williams, C.M. Timperley, L.M. Schopfer, D.M. Cerasoli, O. Lockridge, Production of ES1 plasma carboxylesterase knockout mice for toxicity studies, Chem. Res. Toxicol. 24 (2011) 1891-1898.

[11] C.C. Wong, K.W. Cheng, I. Papayannis, G. Mattheolabakis, L. Huang, G. Xie, N. Ouyang, B. Rigas, Phospho-NSAIDs have enhanced efficacy in mice lacking plasma carboxylesterase: implications for their clinical pharmacology, Pharm. Res. 32 (2015) 1663-1675.

[12] D. Ostergaard, J. Viby-Mogensen, S.N. Rasmussen, M.R. Gatke, F. Varin, Pharmacokinetics and pharmacodynamics of mivacurium in patients phenotypically homozygous for the atypical plasma cholinesterase variant: effect of injection of human cholinesterase, Anesthesiology 102 (2005) 1124-1132.

[13] O. Lockridge, Review of human butyrylcholinesterase structure, function, genetic variants, history of use in the clinic, and potential therapeutic uses, Pharmacol. Ther. 148 (2015) 34-46.

[14] L.M. Schopfer, O. Lockridge, S. Brimijoin, Pure human butyrylcholinesterase hydrolyzes octanoyl ghrelin to desacyl ghrelin, Gen. Comp. Endocrinol. (2015).

[15] K. Mrvova, L. Obzerova, E. Girard, E. Krejci, A. Hrabovska, Monoclonal antibodies to mouse butyrylcholinesterase, Chem. Biol. Interact. 203 (2013) $348-353$.

[16] H. Peng, S. Brimijoin, A. Hrabovska, K. Targosova, E. Krejci, T.A. Blake, R.C. Johnson, P. Masson, O. Lockridge, Comparison of 5 monoclonal antibodies for immunopurification of human butyrylcholinesterase on dynabeads: K values, binding pairs, and amino acid sequences, Chem. Biol. Interact. 240 (2015) 336-345.

[17] J. Hangaard, M. Whittaker, A.G. Loft, B. Norgaard-Pedersen, Quantification and phenotyping of serum cholinesterase by enzyme antigen immunoassay: methodological aspects and clinical applicability, Scand. J. Clin. Lab. Investig. 51 (1991) 349-358.

[18] A. Hrabovska, V. Bernard, E. Krejci, A novel system for the efficient generation of antibodies following immunization of unique knockout mouse strains, PLoS One 5 (2010) e12892.

[19] S. Brimijoin, K.P. Mintz, M.C. Alley, Production and characterization of separate monoclonal antibodies to human acetylcholinesterase and butyrylcholinesterase, Mol. Pharmacol. 24 (1983) 513-520.

[20] F. Checler, J. Grassi, P. Masson, J.P. Vincent, Monoclonal antibodies allow precipitation of esterasic but not peptidasic activities associated with butyrylcholinesterase, J. Neurochem. 55 (1990) 750-755.

[21] G.L. Ellman, K.D. Courtney, V. Andres Jr., R.M. Feather-Stone, A new and rapid colorimetric determination of acetylcholinesterase activity, Biochem. Pharmacol. 7 (1961) 88-95.

[22] J.L. Sporty, S.W. Lemire, E.M. Jakubowski, J.A. Renner, R.A. Evans, R.F. Williams, J.G. Schmidt, M.J. van der Schans, D. Noort, R.C. Johnson, Immunomagnetic separation and quantification of butyrylcholinesterase nerve agent adducts in human serum, Anal. Chem. 82 (2010) 6593-6600.

[23] M.J. Karnovsky, L. Roots, A "Direct-Coloring" thiocholine method for cholinesterases, J. Histochem. Cytochem. 12 (1964) 219-221.

[24] S.F. Altschul, J.C. Wootton, E.M. Gertz, R. Agarwala, A. Morgulis, A.A. Schaffer, Y.K. Yu, Protein database searches using compositionally adjusted substitution matrices, FEBS J. 272 (2005) 5101-5109. 
[25] P. Masson, A naturally occurring molecular form of human plasma cholinesterase is an albumin conjugate, Biochim. Biophys. Acta 998 (1989) 258-266.

[26] K.B. Augustinsson, Electrophoresis studies on blood plasma esterases. I. Mammalian plasmata, Acta Chem. Scand. 13 (1959) 571-592.

[27] K.A. Petrov, E. Girard, A.D. Nikitashina, C. Colasante, V. Bernard, L. Nurullin, J. Leroy, D. Samigullin, O. Colak, E. Nikolsky, B. Plaud, E. Krejci, Schwann cells sense and control acetylcholine spillover at the neuromuscular junction by alpha7 nicotinic receptors and butyrylcholinesterase, J. Neurosci. 34 (2014) $11870-11883$.

[28] K.P. Mintz, R.M. Weinshilboum, W.S. Brimijoin, Evolution of butyrylcholinesterase in higher primates: an immunochemical study, Comp. Biochem. Physiol. C 79 (1984) 35-37.

[29] A.R. Main, S.C. McKnelly, S.K. Burgess-Miller, A subunit-sized butyrylcholinesterase present in high concentrations in pooled rabbit serum, Biochem. J. 167 (1977) 367-376.

[30] O. Jbilo, Y. L'Hermite, V. Talesa, J.P. Toutant, A. Chatonnet, Acetylcholinesterase and butyrylcholinesterase expression in adult rabbit tissues and during development, Eur. J. Biochem. 225 (1994) 115-124.

[31] F.G. Bahar, K. Ohura, T. Ogihara, T. Imai, Species difference of esterase expression and hydrolase activity in plasma, J. Pharm. Sci. 101 (2012) 3979-3988.

[32] F. Margolis, P. Feigelson, Purification and characterization of a genetically determined rabbit serum esterase, J. Biol. Chem. 238 (1963) 2620-2627.

[33] A.R. Main, R.S. Rush, Hydrolysis of choline esters by rabbit liver oligomeric and monomeric carboxylesterases (EC 3.1.1.1), J. Biol. Chem. 255 (1980) $7168-7173$ 